\title{
CONSERVATION BENEFITS OF WHALE WATCHING IN JUNEAU, ALASKA
}

\author{
ALICIA R. SCHULER* AND HEIDI C. PEARSON*† \\ *College of Fisheries and Ocean Sciences, University of Alaska Fairbanks, Juneau, AK, USA \\ †Department of Natural Sciences, University of Alaska Southeast, Juneau, AK, USA
}

\begin{abstract}
An increasing number of visitors to Juneau, AK, alongside a predictable population of humpback whales (Megaptera novaeangliae), has supported the substantial growth of its whale-watching industry. The industry provides benefits to the community through economic gains, while the experience can foster environmental awareness and support for protection of whales and the environment. However, the sustainability of the industry could be jeopardized if increasing whale-watching vessel pressure affects the health of its resource, the whales. This study investigates whether participation in whale-watching tours in Juneau, AK can support conservation of whales and the environment. Participant knowledge, attitudes, intentions, and behaviors were obtained from 2,331 respondents in surveys before, after, and 6 months after a whale-watching tour during the 2016 and 2017 seasons. Following a whale watch, the percentage of participants that indicated whale watching as a knowledge source increased $(p=0.022)$, awareness of guidelines and regulations doubled $(p<0.001)$, and strong support for regulations increased $(p=0.016)$. Six months later, these responses remained significantly higher than before the whale watch. Despite knowledge of distance threshold increasing after a whale watch ( $p=0.003)$ and 6 months after $(p=0.021)$, getting close to whales remained an important factor in a participant's whale watch. Participants had a higher likelihood of strongly supporting guidelines and regulations if they indicated that boats can have a negative impact on whales or were aware of guidelines and regulations. Lastly, participants that acknowledged negative effects on whales from boats had higher overall proenvironmental attitudes. This study indicates that incorporating messages that facilitate participant awareness of guidelines/regulations and the purpose of those measures can support conservation and protection of local whale populations through managing participant expectations and ultimately encouraging operator compliance.
\end{abstract}

\section{Key words: Whale watching; Conservation; Proenvironmental attitudes; Tourism management; Regulation}

Address correspondence to Alicia R. Schuler, College of Fisheries and Ocean Sciences, University of Alaska Fairbanks, 17101 Point Lena Loop Road, Juneau, AK, 99801, USA. E-mail: arschuler@alaska.edu 


\section{Introduction}

Over the last century, the way that people value and interact with whales and dolphins has fundamentally changed. Once extracted and used as an economic commodity, the global moratorium on whaling by the International Whaling Commission in 1986 sought to save the great whales from extinction (International Whaling Commission, 2018). Meanwhile, the demand for seeing whales in the wild has expanded globally since the beginning of whale watching in the 1950s (O'Connor, Campbell, Cortez, \& Knowles, 2009). The global annual economic value for whale watching in 2008 was estimated to be $\$ 2.1$ billion, with over 13 million whale watchers in 119 countries (O'Connor et al., 2009). In the US alone, revenue was estimated to be $\$ 1$ billion, consisting of 5 million whale watchers (O'Connor et al., 2009). Whale watching is often regarded as ecotourism and can benefit communities by stimulating the local economy, providing employment opportunities, and supporting the protection of natural areas and wildlife (Higginbottom, Northrope, \& Green, 2001).

Whale watching can support the protection of whales by providing opportunities for tourists to learn about whales and their environment while experiencing natural areas. Participants often expect to be educated on whale-watching tours, and enjoy learning about whales and the marine environment (Filby, Stockin, \& Scarpaci, 2015; Lück, 2003; Russell \& Hodson, 2002). Following a whale-watching tour, participants have demonstrated greater knowledge about cetaceans (Filby et al., 2015; Mayes \& Richins, 2009), awareness of threats to cetaceans (Filby et al., 2015; Finkler \& Higham, 2004), greater proenvironmental attitudes (Christensen, Rowe, \& Needham, 2007), and increased support for conservation of whales and marine environments (Christensen, Needham, \& Rowe, 2009). In the long term, previous studies have indicated that the experience and knowledge obtained from the whale-watching tour can contribute towards lasting proenvironmental attitudes and behaviors (Orams, 1997; Zeppel \& Muloin, 2008).

By contrast, others argue that ecotourism can lack conservation gain and harm the natural resources upon which the industry depends (Steele, 1993). Education programs can be ineffective because environmental knowledge alone is not enough to influence environmental attitudes and behaviors (Beaumont, 2001; Gralton, Sinclair, \& Purnell, 2004). Also, Stamation, Croft, Shaughnessy, Waples, and Briggs (2007) determined that while participants indicated knowledge and proenvironmental intentions following their whale-watching tour, they were unlikely to remember what they learned during their whale watch experience and did not change the rate at which they carried out proenvironmental behaviors 6-8 months later. The presence of the whale-watching vessels themselves may also negatively impact the whales (Parsons, 2012). Whales have demonstrated changes in direction, higher speeds, and higher breath rates in the presence of whale-watching vessels (Schuler, et al., 2019). These short-term changes can accumulate to long-term fitness consequences for whales if more time and energy is spent avoiding vessels than performing behaviors such as foraging and resting that are essential for body maintenance (Lusseau \& Bejder, 2007; Parsons, 2012). Disturbances from vessel presence may also result in whales altering their distribution and habitat use (Bejder et al., 2006; Cartwright et al., 2012).

Many regions have created guidelines and regulations to mitigate potential disturbance to whales by whale-watching vessels (Carlson, 2013). In the US, each National Oceanic and Atmosphere Administration (NOAA) Fisheries Regional Office develops whale-watching guidelines and regulations to support protections under the Marine Mammal Protection Act (MMPA). Further efforts to manage local industries include voluntary programs, like Whale SENSE (NOAA Fisheries \& Whale and Dolphin Conservation, 2018), that exist in the Atlantic and Alaska regions. This program recognizes and promotes operators that agree to follow additional viewing guidelines and complete annual staff trainings to support accurate educational messages on tours. Incorporating an explanation of guidelines and regulations has the potential to be a proactive management strategy to avoid negatively affecting whale populations where whale-watching industries exist (Andersen \& Miller, 2006). Further, increasing whale watch participant knowledge and awareness has been found to encourage operator compliance to regulations (Filby et al., 2015). 
The whale-watching industry in Juneau, Alaska has become increasingly lucrative alongside a growing number of cruise ship passengers that visit from May to September. As a city only accessible by boat or by plane, cruise ships contribute $93 \%$ of all visitors to Juneau, totaling over 1 million people each year (McDowell Group, 2017). Approximately one third of visitors participated in whale watching and other day cruises in 2016 (McDowell Group, 2017). The annual revenue of the whale-watching industry was estimated to be \$32 million in 2006 (Dugan, Fay, Griego, \& Colt, 2009); however, the industry has likely increased in value since then. From 2006 to 2018, the number of visitors in Juneau grew by $23 \%$ and this number was projected to be 48\% higher in 2019 versus 2018 (Rain Coast Data, 2018). A reliable presence of humpback whales (Megaptera novaeangliae) and opportunistic sightings of killer whales (Orcinus orca) has resulted in all dedicated whale-watching operations offering a whale sighting money back guarantee (S. Teerlink, Alaska Regional Office, NMFS, personal communication, February 18, 2019). The Juneau whalewatching industry consists of approximately 65 dedicated whale-watching vessels, in addition to opportunistic whale watching that occurs with fishing charter vessels (Di Clemente et al., 2018). Of the vessels that offered dedicated whale-watching tours in Juneau in 2018, approximately 67\% participated in the Whale SENSE program (Schuler, unpublished data).

As more people participate in whale-watching tours and whale-watching vessel presence increases, it is essential to create a sustainable industry that supports conservation and protection of whales. The overall goal of this study was to determine whether whale-watching tours in Juneau can support the conservation of whales and the environment. The first objective (Objective 1) of this study was to identify differences in whale-watching participants' knowledge, intentions, behaviors, and attitudes before, after, and 6 months after a whalewatching tour. The second objective (Objective 2) of this study was to determine how awareness of whale-watching guidelines and regulations, behaviors, attitudes, and demographics influenced whalewatching participants' support of guidelines and regulations. The third objective (Objective 3) of this study was to evaluate whether whale-watching participants' behaviors, attitudes towards whale watching, and survey group related to proenvironmental attitudes.

\section{Method}

Paper-and-pencil multiple answer choice surveys were administered by a researcher (A.S.) to participants before (PRE) (surveys are available upon request) or after (POST) a whale-watching tour to measure knowledge, intentions, behaviors, and attitudes in addition to demographic information. Six months later (POST6M), participants who provided their email address received a survey on the Survey Monkey website. The majority of whale-watching tours depart from Auke Bay, approximately 12 miles from downtown Juneau. Since most tourists to Juneau arrive by cruise ship, companies arrange for shuttle buses to pick up and drop off participants at the cruise ship terminal. Participants in this study completed the 5-min survey on the shuttle bus to or from the whale-watching tour. Participants were informed about the goals of the project and notified of the requirements for participating. Survey participation was voluntary, and all survey participants met inclusion criteria of being 18 years or older and able to read and understand spoken and written English. Inclusion criteria were verified by questioning each person individually. Upon completion of the survey, participants were encouraged to include their email address to be entered to win a \$50 Amazon gift card. Of the approximately 16 whale-watching companies in Juneau, three whalewatching companies participated in implementing the surveys. Two companies were selected opportunistically and one was a participant in previous research (Lopez \& Pearson, 2017). To be included in the study, a $75 \%$ completion rate was required for each survey. All research was carried out under approval of the University of Alaska Southeast Institutional Review Board (\#16-13).

\section{Participants}

Survey group was defined by the period of time in which participants completed the survey (PRE, POST, POST6M). Demographic information was included as a series of open-response questions for nationality and sex. Preselected options were 
presented for age (18-24, 25-40, 41-60, 60+). For regression analysis, nationality was recoded to "USA" versus "Other." Experience was determined by the total number of whale-watching tours the participant had partaken in prior to Juneau. For comparisons between survey groups, experience was further divided into "First time" whale watchers and "Experienced" (0 and 1, respectively).

\section{Knowledge}

Participants were asked to choose a single response to "How have you gained most of your knowledge about whales?” from preselected options (e.g., TV/movies, internet, whale watch). Participants also responded to "Are you aware of any whale watch guidelines/regulations?” by selecting "Yes" or "No" to determine perceived awareness of NOAA humpback whale approach guidelines and regulations. For those who selected "Yes," knowledge of guidelines and regulations was indicated if they correctly selected all listed guidelines and regulations. In 2016, the Alaska Humpback Whale Approach Regulations required that operators: 1) not approach within 100 yards of a humpback whale, 2) not place the vessel in the path of oncoming humpback whales causing them to surface within 100 yards of the vessel, and 3) operate at a slow, safe speed when near humpback whales (National Oceanic and Atmospheric Administration, 2016). In 2017, the regulation "Not disrupt the normal behavior or prior activity of a whale" was added by NOAA. The General Marine Mammal Viewing Code of Conduct (NOAA Fisheries, 2019) and Whale SENSE guidelines also suggest limiting time observing individuals to $30 \mathrm{~min}$.

\section{Behaviors and Intentions}

Preselected options for environmental behaviors (e.g., recycling, composting, and energy usage) were listed for participants to "Check all that apply" to "Which of the following environmental activities do you do?" Selected behaviors were recoded as a "Yes" response, while unselected behaviors were recoded as "No." Intention after their whale watch in Juneau was determined by the likelihood of participants to engage in conservation behaviors (i.e., "Go on another whale watch or marine ecotourism trip," "Join or donate to an environmental or conservation organization," and "Tell your friends and family about what you learned"). Responses were on a 3-point Likert-type scale including Not likely, Somewhat likely, and Very likely. Six months later, participants were asked if they had fulfilled those intentions since their whale watch in Juneau by selecting "Yes" or "No."

\section{Attitudes}

Participant attitudes towards whale watching were evaluated by importance factors and responses regarding the effects of viewing whales from boats. In response to "Which of the following is/was the single most important factor in determining the quality of your whale watch experience?” participants selected one of preselected options (i.e., "getting close to whales," "boat size and number of passengers on board," "seeing the whales do interesting behaviors like feed or leap," "being with the whales for a long time," "being the only boat with the whales," "being respectful to the whales"). In response to "How important is it to you personally to be able to see humpback whales in the wild?" a 3-point Likert-type scale included Not important, Somewhat important, and Very important. Participants indicated their agreement or disagreement towards effects of whale watching (i.e., "Observing whales from boats can have negative impacts on whales," "Observing whales from boats can have positive impacts on people," "Following whale watch guidelines and regulations is important for the protection of whales") on a 5-point Likert-type scale including Strongly disagree, Disagree, Neither agree nor disagree, Agree, and Strongly agree. In regression analyses, when used as independent variables, statements regarding the effects of whale watching were recoded to a 3-point Likert-type scale (Disagree, Neutral, Agree).

Environmental attitudes were assessed using the modified New Environmental Paradigm (NEP) scale by Luzar, Diagne, Gan, and Henning (1995). The NEP uses six 5-item Likert-type scale statements concerning human conflicts with nature, limits to growth, and the role of humans in nature 
to measure overall participant pro-environmental attitudes. NEP responses have a value from 1 to 5 , with responses reflecting positive environmental attitudes ranking higher. The maximum total score for the modified NEP scale is 30 .

\section{Social Desirability}

The 5-item Socially Desirable Response Set (SDRS) was included to control for socially desirable response tendencies (Hays, Hayashi, \& Stewart, 1989). Social desirability is an individual's tendency to portray a positive self-image at the expense of presenting factual information (Hays et al., 1989). By measuring social desirability, the study controlled for socially desirable responses concerning prosocial behaviors such as environmental and conservation actions (Pearson, Dawson, \& Radecki Breitkopf, 2012). SDRS was included as a covariate in all multivariate models.

\section{Statistical Methods}

All analyses were performed using the free, opensource software R v.3.4.3 (https://www.R-project. org/). For analysis of Objective 1, participant responses regarding knowledge, intentions, behaviors, and attitudes were compared across all survey groups (PRE, POST, and POST6M) using Pearson chi-square tests. Intentions and previous whalewatching experience were also compared within survey groups using Pearson chi-square tests. Likerttype scale questions on attitudes towards whale watching for each survey group were compared using Wilcoxon rank sum tests.

Post hoc analysis for Objective 2 indicated that responses to "Following whale watch guidelines and regulations is important for the protection of whales” lacked variability and would have caused analytic problems, with the majority of responses being Agree (26\%) or Strongly agree (64\%). This may be due to the highly socially desirable nature of an agreeable response. Therefore, after Radecki Breitkopf and Pearson (2009), responses to the dependent variable "Following whale watch guidelines and regulations is important for the protection of whales" were recoded as Strongly agree versus "Other" responses (Strongly disagree, Disagree, Neutral, Agree).
To further analyze Objective 2, Pearson chisquare tests were used to determine significant differences in Strongly agree versus “Other” responses to "Following whale watch guidelines and regulations is important for the protection of whales" in relation to each explanatory variable. Explanatory variables included awareness about whale-watching guidelines and regulations, behaviors (i.e., "belong to an environmental or conservation organization”), importance factors, attitudes regarding whale watching, NEP, and demographics (i.e., nationality, sex, and age). Significant variables at the bivariate level were then entered into a multivariate model. Binomial logistic regression was used to predict the probability of a participant choosing Strongly agree versus "Other" responses, while controlling for SDRS and survey group. A likelihood ratio test was used to determine the best fit model. The probability of choosing Strongly agree, the odds ratio (probability of choosing Strongly agree divided by the probability of choosing “Other”) and a 95\% confidence interval for the odds ratio were estimated.

In support of Objective 3, analysis of variance (ANOVA) and pairwise $t$ tests were used to determine which explanatory variables affected participant NEP score. Explanatory variables tested included behaviors (recycling at home, membership to an environmental or conservation organization), importance factors, attitudes regarding whale watching, and survey group. Significant variables were then included in the linear regression model while controlling for SDRS and demographics (i.e., nationality, age, and sex).

\section{Results}

\section{Participants}

Of the 2,385 surveys completed, 2\% ( $n=54)$ were removed due to $<75 \%$ completion rate, resulting in a total of 2,331 surveys used in analyses (PRE: $n=971$, POST: $n=1,167$, POST6M: $n=193)$. Of the number of participants invited to take the survey in 2017, the response rate for the PRE and POST was 60\% (this information was not collected in 2016). Participants were primarily from the US (81\%), with the rest from other countries ("Other") (17\%) (Table 1). The majority of participants were female and over the age of 40 . 
Table 1

Passenger Responses to the Demographic Questions on the Multiple Choice Survey (PRE and POST, $N=2,138$ )

\begin{tabular}{lc}
\hline Survey Item & $\%(n)$ \\
\hline Age & \\
$18-25$ & $6.3 \%(135)$ \\
$26-40$ & $18.0 \%(384)$ \\
$41-60$ & $42.1 \%(901)$ \\
$60+$ & $30.1 \%(643)$ \\
Sex & \\
Female & $54.6 \%(1,168)$ \\
Male & $35.0 \%(748)$ \\
Nationality & \\
USA & $80.8 \%(1727)$ \\
Other & $16.7 \%(358)$ \\
$\quad$ Europe & $4.3 \%(94)$ \\
$\quad$ Australia/New Zealand & $4.2 \%(89)$ \\
$\quad$ Canada & $3.4 \%(72)$ \\
Asia & $2.1 \%(46)$ \\
\hline
\end{tabular}

Note. Totals that do not equal $100 \%$ or $N=2,138$ reflect missing data.

There were no significant differences in demographic distributions between the PRE, POST, or POST6M survey groups. For the majority of participants, their whale watch in Juneau was their first whale watch (PRE: 54\%, POST: 64\%, POST6M: $55 \%)$.

\section{Objective 1}

PRE participants attained knowledge about whales primarily through TV and movies (Fig. 1). There was a significant decrease in the proportion of participants that selected TV and movies between the PRE versus POST ( $p=0.022)$ and PRE versus POST6M $(p<0.001)$. Instead, the majority of the POST and POST6M participants indicated that their whale watch in Juneau was their primary source of whale information.

The percentage of participants who indicated awareness about guidelines and regulations was double in POST compared to PRE ( $p<0.001$, Table 2$)$. Of those who indicated that they were aware of NOAA whale watch guidelines, there was an increase in the percentage of participants who knew "Maintaining a distance of at least 100 yards from humpback whales" between PRE versus POST ( $p=0.003$ ) and PRE versus POST6M $(p=0.021)$ and the percentage of participants who knew "Staying with humpback whales for a maximum of 30 minutes" between PRE versus POST $(p=0.026)$ and PRE versus POST6M $(p=0.002)$. The percentage of participants that correctly selected all of the guidelines and regulations listed doubled between the PRE versus POST6M $(p=0.008)$.

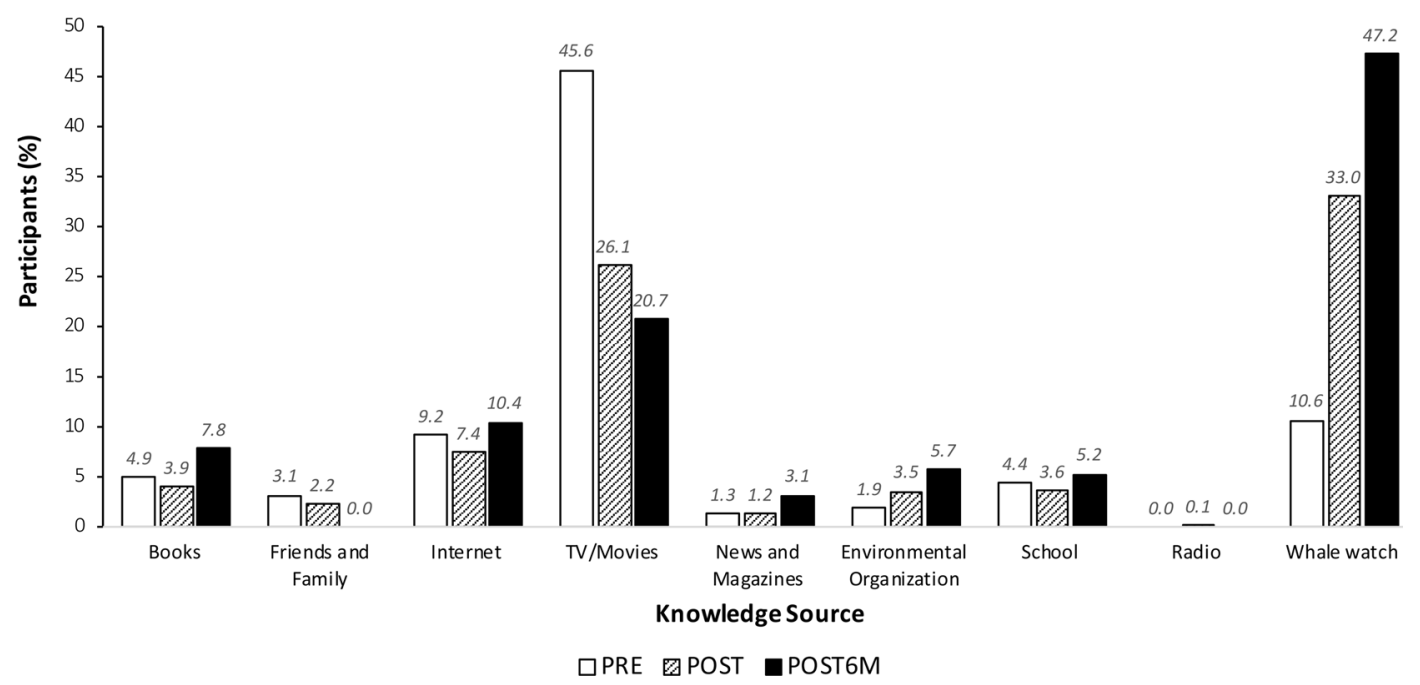

Figure 1. Distribution of passenger-selected sources in response to the multiple answer choice question: "How have you gained most of your knowledge about whales?” Percentages are presented above each bar. 


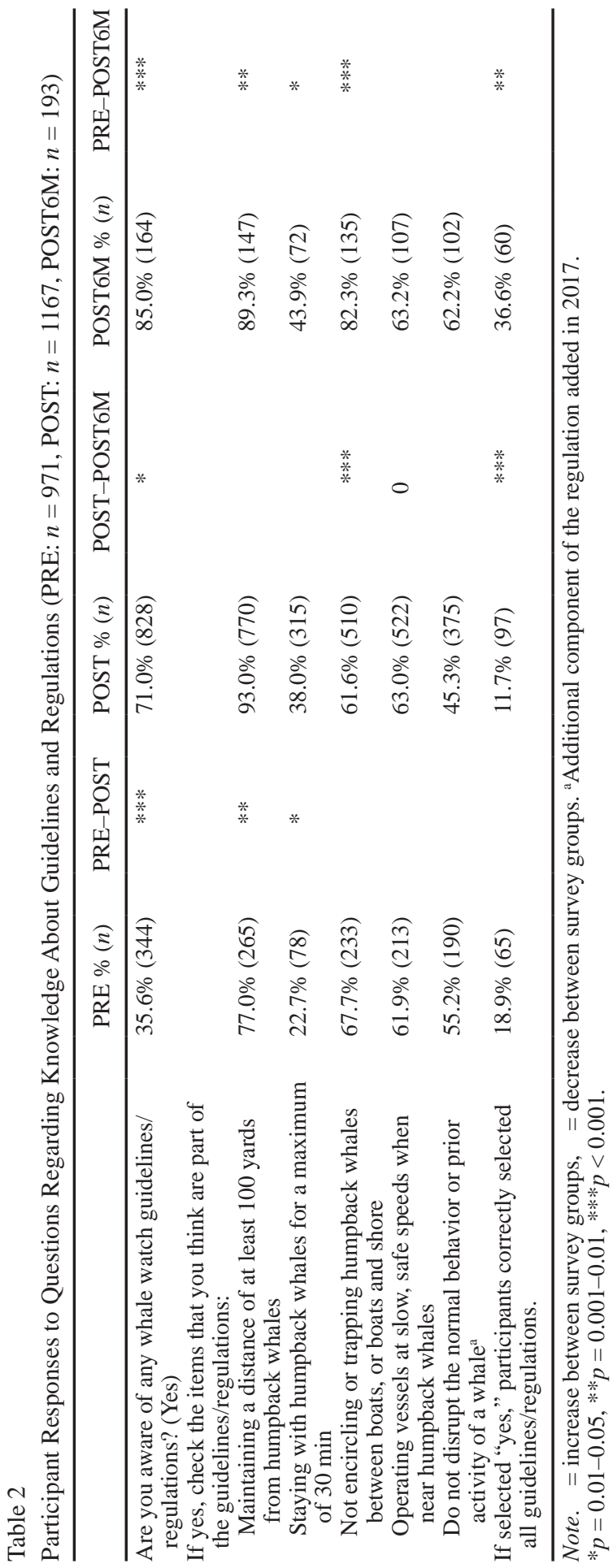

The majority of POST participants indicated that after their whale watch in Juneau, they were very likely to "Go on another whale watch or marine ecotourism trip" and "Tell your friends and family about what you learned” (Table 3). Meanwhile, nearly a quarter of participants were very likely to "Join or donate to an environmental or conservation organization.” In comparison to participants that indicated Very likely responses in the POST, there were fewer participants 6 months after the whale watch in Juneau (POST6M) that indicated "Yes" to having "Gone on another whale watch or marine ecotourism trip" $(p<0.001)$ and less that indicated "Yes" to "Joined or donated to an environmental or conservation organization” ( $p=0.043)$. However, percentage of POST6M participants that told their friends and family about what they learned was higher than those that indicated Very likely intentions in the POST ( $p=0.018)$.

Previous whale-watching experience did not have a significant effect on POST or POST6M participants' intentions to "Join or donate to an environmental or conservation organization" or "Tell friends and family about what you learned.” It also did not affect POST participants' likelihood to "Go on another whale-watching or ecotourism trip", but POST6M participants with previous whalewatching experience prior to Juneau were significantly more likely to have gone on another whalewatching or ecotourism trip 6 months later $(p<$ 0.001) (Table 4).

The mean number of preselected environmental behaviors in which participants from each survey group engaged was three [PRE: $3 \pm 1.5$ $(n=971$ range $=1-8)$, POST: $3 \pm 1.6(n=1,167$, range $=1-8$, POST6M: $3 \pm 1.7$, range $=1-8)$ ]. At least $95 \%$ of participants in all survey groups selected at least one environmental behavior. While all environmental behaviors increased POST6M compared to PRE and POST, the only significant result was an increase in "Conserve energy at home” from PRE to POST6M ( $p<0.05)$ (Table 5). For all survey groups, the majority of participants selected "Recycle at home" and "Conserve energy at home” as environmental behaviors that they participate in, while the least participated in environmental behaviors were "Vegetarianism" and "Belong to an environmental organization or charity." 
Table 3

Intention following whale watching trip

\begin{tabular}{|c|c|c|c|c|}
\hline \multicolumn{2}{|c|}{$\begin{array}{l}\text { After your whale watch in Juneau, } \\
\text { how likely would you be to: }\end{array}$} & \multicolumn{2}{|c|}{$\begin{array}{l}\text { After your whale watch in } \\
\text { Juneau, did you: }\end{array}$} & \multirow{2}{*}{$\begin{array}{c}\text { Very Likely } \\
\text { Versus Yes } \\
\text { POST-POST6M }\end{array}$} \\
\hline POST & $\%(n)$ & POST6M & $\%(n)$ & \\
\hline \multicolumn{5}{|c|}{$\begin{array}{l}\text { Go on another whale watch or } \\
\text { marine ecotourism trip? }\end{array}$} \\
\hline Very likely & $67.2 \%(784)$ & Yes & $6.2 \%(12)$ & $\downarrow * * *$ \\
\hline Somewhat likely & $26.8 \%$ (313) & No & 93.3\% (180) & \\
\hline Not likely & $5.5 \%(64)$ & & & \\
\hline \multicolumn{5}{|c|}{$\begin{array}{l}\text { Join or donate to an environmental } \\
\text { or conservation organization? }\end{array}$} \\
\hline Very likely & $23.3 \%(272)$ & Yes & $11.9 \%(23)$ & $\downarrow *$ \\
\hline Somewhat likely & $50.0 \%(583)$ & No & $87.0 \%$ (168) & \\
\hline Not likely & $23.0 \%(268)$ & & & \\
\hline \multicolumn{5}{|c|}{$\begin{array}{l}\text { Tell your friends and family about } \\
\text { what you learned? }\end{array}$} \\
\hline Very likely & $80.4 \%$ (938) & Yes & $94.3 \%$ (182) & $\uparrow^{*}$ \\
\hline Somewhat likely & $15.4 \%(180)$ & No & $5.7 \%(11)$ & \\
\hline Not likely & $1.5 \%(18)$ & & & \\
\hline
\end{tabular}

Note. Totals that do not equal $100 \%$ or $N=1167$ (POST), $N=193$ (POST6M) reflect missing data. $\uparrow=$ increase between survey groups, $\downarrow=$ decrease between survey groups. ${ }^{*} p=0.01-0.05, * * * p<0.001$.

The majority of participants in all survey groups indicated that it was very important for them to personally see humpback whales in the wild, with no significant difference in responses between survey groups (PRE: 62\%, POST: 61\%, POST6M: $72 \%)$. The top PRE responses to "Which of the following was the single most important factor in determining the quality of your whale watch experience in Juneau?" were "getting close to the whales" and "seeing the whales do interesting behaviors like feed or leap." For both POST and POST6M, these remained as the top importance factors, with no significant difference between survey groups (Fig. 2).The percentage of participants that indicated awareness of the NOAA regulation "Maintaining a distance of at least 100 yards from humpback whales" did not significantly affect their selection of "getting close to the whales" as the single most important factor (PRE: 22\%, POST: 40\%, POST6M: 29\%).

The majority of participants agreed or strongly agreed that "Following whale watch guidelines and regulations is important for the protection of whales," with the percentage that strongly agreed significantly increasing between PRE versus POST $(p=0.016)$ and PRE versus POST6M $(p=0.008)$
(PRE: 60\%, POST: 66\%, POST6M: 73\%) (Fig. 3). Approximately half of participants were neutral on the statement "Observing whales from boats can have negative impacts on whales" (PRE: 51\%, POST: $40 \%$, POST6M: 47\%), with the percentage of participants who disagreed higher in the POST versus PRE $(p<0.001)$ and lower in POST6M versus POST $(p<0.001)$ (PRE: $27 \%$, POST: $35 \%$, POST6M: 28\%). The majority of participants agreed or strongly agreed that "Observing whales from boats can have positive impacts on people," with the percentage that strongly agreed higher in POST6M versus PRE $(p=0.001)$ and POST6M versus POST ( $p=0.011$ ) (PRE: 22\%, POST: $27 \%$, POST6M: 37\%).

NEP values ranged from 6 to 30. Mean NEP score was not significantly different between survey groups [PRE: $24 \pm 3.8(n=971$, range $=$ 11-30), POST: $24 \pm 4.1(n=1167$, range $=6-30)$, POST6M: $24 \pm 3.8(n=193$, range $=10-30)]$.

\section{Objective 2}

To determine variation in Strongly agree versus “Other” (Strongly disagree, Disagree, Neutral, Agree) in response to "Following whale 
Table 4

POST and POST6M Participants' Intention According to Previous Whale Watch (WW) Experience

\begin{tabular}{|c|c|c|c|c|c|}
\hline & $\begin{array}{l}\text { First WW } \\
\%(n)\end{array}$ & $\begin{array}{l}\geq 1 \mathrm{WW} \\
\%(n)\end{array}$ & Pearson $x^{2}$ & $d f$ & $p$ \\
\hline \multicolumn{6}{|c|}{$\begin{array}{l}\text { After your whale watch in Juneau, how likely would } \\
\text { you be to: (POST) }\end{array}$} \\
\hline \multicolumn{6}{|c|}{$\begin{array}{l}\text { Go on another whale watch or marine ecotourism } \\
\text { trip? }\end{array}$} \\
\hline Very likely & $61.4 \%(461)$ & 77.6\% (323) & 5.8667 & 2 & 0.053 \\
\hline Somewhat likely & $31.4 \%$ (236) & $18.5 \%(77)$ & & & \\
\hline Not likely & $6.4 \%(48)$ & $3.9 \%(16)$ & & & \\
\hline \multicolumn{6}{|c|}{$\begin{array}{l}\text { Join or donate to an environmental or conservation } \\
\text { organization? }\end{array}$} \\
\hline Very likely & 22.5\% (169) & $24.8 \%(103)$ & 0.25412 & 2 & 0.881 \\
\hline Somewhat likely & $49.4 \%(371)$ & $51.0 \%(212)$ & & & \\
\hline Not likely & 23.8 (179) & 21.4 (89) & & & \\
\hline \multicolumn{6}{|c|}{$\begin{array}{l}\text { Tell your friends and family about what you } \\
\text { learned? }\end{array}$} \\
\hline Very likely & $80.2 \%(602)$ & $80.8 \%$ (336) & 0.27636 & 2 & 0.871 \\
\hline Somewhat likely & $15.6 \%$ (117) & $15.1 \%(63)$ & & & \\
\hline Not likely & $1.2 \%(9)$ & $2.2 \%(9)$ & & & \\
\hline \multicolumn{6}{|c|}{$\begin{array}{l}\text { After your whale watch in Juneau, did you: } \\
\text { (POST6M) }\end{array}$} \\
\hline \multicolumn{6}{|c|}{$\begin{array}{l}\text { Go on another whale watch or marine ecotourism } \\
\text { trip? }\end{array}$} \\
\hline Yes & $0.0 \%(0)$ & $13.8 \%(12)$ & 12.906 & 1 & $<0.001$ \\
\hline No & $100.0 \%(106)$ & $85.1 \%(74)$ & & & \\
\hline \multicolumn{6}{|c|}{$\begin{array}{l}\text { Join or donate to an environmental or conservation } \\
\text { organization? }\end{array}$} \\
\hline Yes & $10.4 \%(11)$ & $13.8 \%(12)$ & 0.34143 & 1 & 0.559 \\
\hline & $89.6 \%(95)$ & $83.9 \%$ (73) & & & \\
\hline \multicolumn{6}{|c|}{$\begin{array}{l}\text { Tell your friends and family about what you } \\
\text { learned? }\end{array}$} \\
\hline Yes & 95.3\% (106) & $93.1 \%(81)$ & 0.12722 & 1 & 0.721 \\
\hline No & $4.7 \%(5)$ & $6.9 \%(6)$ & & & \\
\hline
\end{tabular}

Note. Totals that do not equal 100\% or $N=1,167$ (POST), $N=193$ (POST6M) reflect missing data. Significant $p$-value is shown in italic.

Table 5

Participant Responses to "Which of the Following Environmental Activities do you do? Check all That apply"

\begin{tabular}{|c|c|c|c|c|c|}
\hline & PRE \% (n) & POST \% (n) & POST-POST6M & $\begin{array}{l}\text { POST6M } \\
\%(n)\end{array}$ & PRE-POST6M \\
\hline Recycle at home & $80.0 \%(777)$ & $83.3 \%(972)$ & $\uparrow$ & $86.5 \%(167)$ & $\uparrow$ \\
\hline Recycle at work & $51.3 \%(498)$ & $53.9 \%(629)$ & $\uparrow$ & $59.1 \%(114)$ & $\uparrow$ \\
\hline Conserve energy at home & $70.7 \%(686)$ & $74.7 \%(872)$ & $\uparrow$ & $83.9 \%(162)$ & $\uparrow *$ \\
\hline Vegetarianism & $4.7 \%(46)$ & $6.3 \%(74)$ & $\downarrow$ & $4.2 \%(8)$ & 0 \\
\hline Avoid cosmetics tested on animals & $24.2 \%(235)$ & $25.2 \%(294)$ & $\uparrow$ & $30.6 \%(59)$ & $\uparrow$ \\
\hline Avoid using the car when possible & $17.0 \%(165)$ & $19.7 \%(230)$ & $\uparrow$ & $27.5 \%(53)$ & $\uparrow$ \\
\hline Compost & $16.4 \%(159)$ & $21.6 \%(252)$ & $\uparrow$ & $25.9 \%(50)$ & $\uparrow$ \\
\hline $\begin{array}{l}\text { Belong to an environmental or } \\
\text { conservation organization }\end{array}$ & $7.3 \%(71)$ & $9.9 \%(116)$ & $\uparrow$ & $13.5 \%(26)$ & $\uparrow$ \\
\hline None of the above & $5.0 \%(48)$ & $3.9 \%(45)$ & $\downarrow$ & $0.5 \%(1)$ & $\downarrow$ \\
\hline
\end{tabular}

Note. $\uparrow=$ increase between survey groups, $\downarrow=$ decrease between survey groups.

$* p<0.05$. 


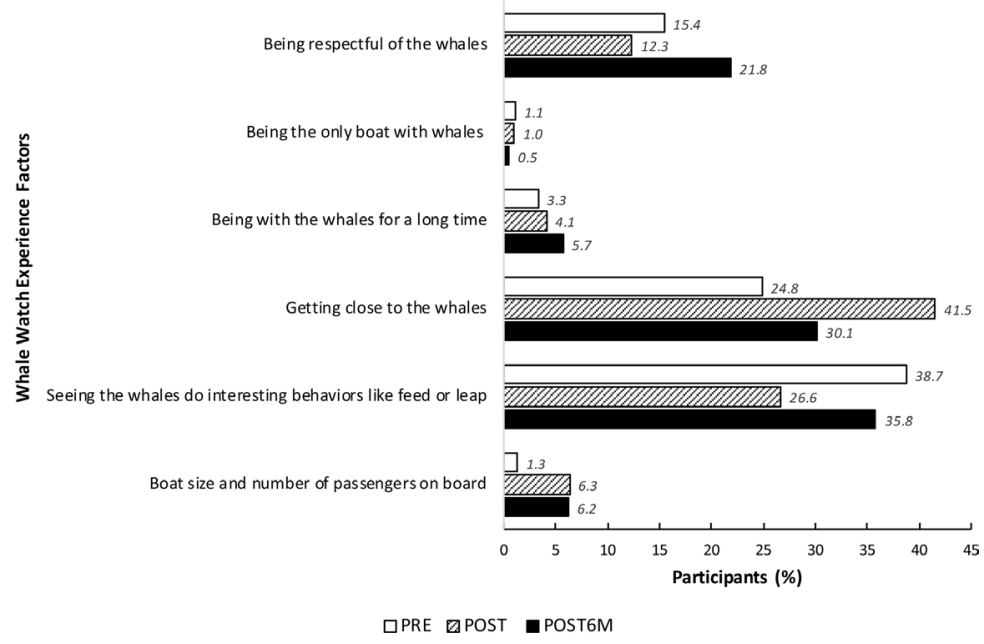

Figure 2. Participant responses to the multiple answer choice question: "Which of the following do you think will be/was the single most important factor in determining the quality of your whale watch experience?” Percentages are presented next to each bar.

watch guidelines and regulations is important for the protection of humpback whales," significant explanatory variables for the strongest model using bivariate analyses and likelihood ratio tests included: awareness of guidelines and regulations, attitudes towards importance factors, attitudes towards negative effects of whale-watching vessels, NEP, nationality, sex, and age (Table 6). While survey group was significant in bivariate analysis, likelihood ratio tests indicated that it did not contribute to the best model. In response to "Are you aware of any whale watch guidelines/regulations?" participants that selected "Yes" rather than "No" were $46 \%$ more likely to

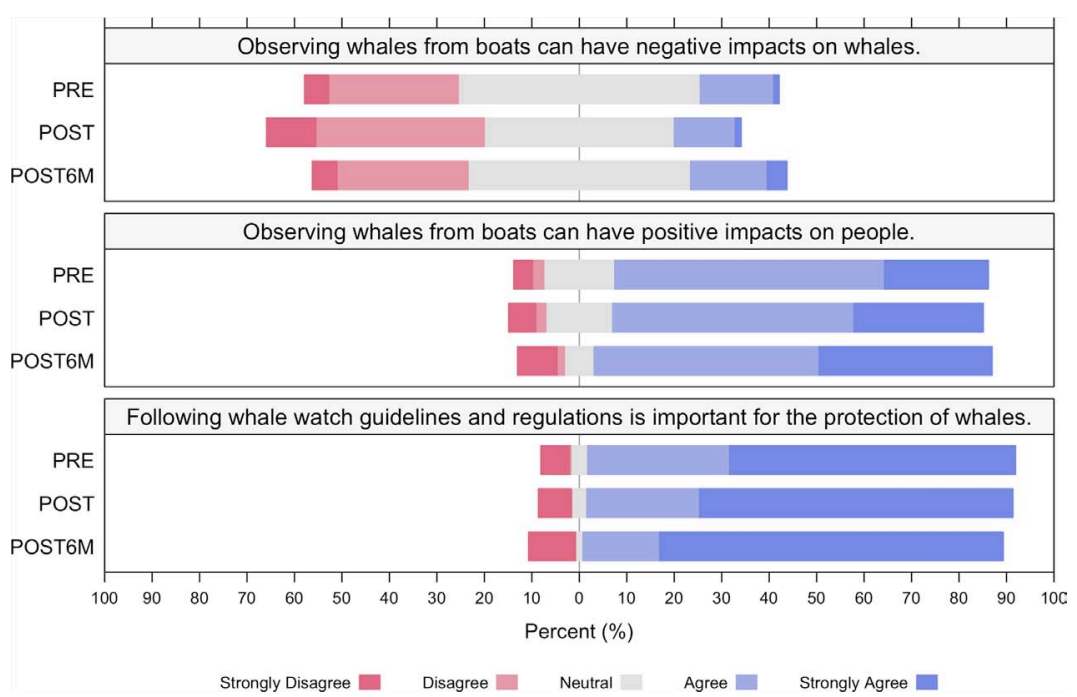

Figure 3. Participant's attitudes regarding whale watching on a Likert-type scale (PRE: $n=963$, POST: $n=1,136$, POST6M: $n=192$ ). 
choose Strongly agree over "Other" responses [odds ratio: $1.460,95 \%$ CI $(1.249,1.668)]$. In response to "Which of the following was the single most important factor in determining the quality of your whale watch experience?” participants that selected "being respectful of the whales" rather than "getting close to the whales" were $44 \%$ more likely to choose Strongly agree over "Other" responses [odds ratio: 1.442, 95\% CI $(1.012,2.053)]$. In response to "How important is it to you personally to be able to see humpback whales in the wild?" participants that selected Somewhat important versus Very important were $60 \%$ as likely to select Strongly agree over “Other" responses [odds ratio: 0.596 (95\% CI $(0.474,0.749)]$. Compared to participants that agreed that "Observing whales from boats can have negative impacts on whales," those that were neutral were $68 \%$ as likely to select Strongly agree [odds ratio: 0.684 , (95\% CI $(0.486,0.967)$ ] and those that disagreed were $65 \%$ as likely to select Strongly agree [odds ratio: 0.649, (95\% CI (0.457, 0.922)]. For each unit increase in participant NEP score, the odds of choosing Strongly agree over "Other" responses increased by 15\% [odds ratio: 1.147, (95\% CI $(1.114,1.182)]$. Also, males were $77 \%$ as likely to select Strongly agree as females [odds ratio: 0.769, (95\% CI $(0.617,0.959)$ ] and participants of "USA" nationality were $54 \%$ more likely to select Strongly agree than those from "Other" nationalities [odds ratio: 1.541 (95\% CI (1.134, 2.094)].

Table 6

Logistic Regression Output for Predicting the Probability of Participants Selecting Strongly agree Versus “Other” Responses (Strongly disagree, Disagree, Neutral, Agree) to "Following Whale Watch Guidelines and Regulations Is Important for the Protection of Humpback Whales"

\begin{tabular}{lcccc}
\hline & Estimate & $S E$ & $z$ Value & $\operatorname{Pr}(>|z|)$ \\
\hline Intercept) & -2.010 & 0.485 & -4.146 & $<0.0011$ \\
Awareness of guidelines/regulations: No & Ref & Ref & Ref & Ref \\
Awareness of guidelines/regulations: Yes & 0.378 & 0.080 & 4.749 & $<0.001$ \\
Belong to an organization: No & Ref & Ref & Ref & Ref \\
Belong to an organization: Yes & 0.202 & 0.213 & 0.948 & 0.343 \\
Importance factor: Getting close & Ref & Ref & Ref & Ref \\
Importance factor: Boat size & 0.430 & 0.278 & 1.546 & 0.122 \\
Importance factor: See behaviors like feed or leap & 0.003 & 0.125 & 0.021 & 0.983 \\
Importance factor: Long time with whales & -0.086 & 0.268 & -0.321 & 0.748 \\
Importance factor: Only boat & 0.081 & 0.504 & 0.161 & 0.872 \\
Importance factor: Being respectful to whales & 0.366 & 0.180 & 2.029 & 0.042 \\
See whales in the wild: Very important & Ref & Ref & Ref & Ref \\
See whales in the wild: Somewhat important & -0.518 & 0.117 & -4.428 & $<0.001$ \\
See whales in the wild: Not important & -0.350 & 0.268 & -1.305 & 0.192 \\
Boats have negative effects: Agree & Ref & Ref & Ref & Ref \\
Boat have negative effects: Neutral & -0.379 & 0.176 & -2.152 & 0.031 \\
Boat have negative effects: Disagree & -0.432 & 0.179 & -2.412 & 0.016 \\
NEP & 0.137 & 0.015 & 9.059 & $<0.001$ \\
SDRS & 0.014 & 0.042 & 0.343 & 0.731 \\
Nationality: Other & Ref & Ref & Ref & Ref \\
Nationality: USA & 0.432 & 0.156 & 2.766 & 0.006 \\
Sex - Female & Ref & Ref & Ref & Ref \\
Sex: Male & -0.262 & 0.112 & -2.334 & 0.020 \\
Age: 18-25 & Ref & Ref & Ref & Ref \\
Age: 26-40 & -0.254 & 0.262 & -0.970 & 0.332 \\
Age: 41-60 & -0.415 & 0.244 & -1.705 & 0.088 \\
Age: 60+ & -0.562 & 0.250 & -2.252 & 0.024 \\
\hline Note. Predictor variaf & & & & \\
& & & &
\end{tabular}

Note. Predictor variables included awareness of guidelines/regulations, attitudes towards whale watching, proenvironmental attitudes (NEP), and demographics (nationality, sex, age), while controlling for SDRS. Ref = reference group in the analysis. Significant $p$ values are shown in italic. 


\section{Objective 3}

Bivariate analysis indicated that behaviors ("Recycle at home" and "Belong to an environmental or conservation organization”), importance factors, attitudes towards whale watching, nationality, and sex were all significant explanatory variables in determining variance in NEP scores. Participants that recycled at home or were a part of an environmental organization had a significantly higher NEP score than those that did not (Table 7). In comparison to "getting close to the whales" as the single most important factor, participants that indicated "being respectful to the whales" had a significantly higher NEP score. In response to "Following whale watch guidelines and regulations are important for the protection of whales," participants that were neutral had a significantly lower NEP score than those that agreed. However, NEP score was not significantly different in those that disagreed compared to those that agreed. In comparison to participants that agreed in response to "Observing whales from boats can have negative impacts on whales," participants had a significantly lower NEP score if they were neutral or disagreed. Males had a significantly lower NEP score than females and participants of "USA" nationality had a significantly lower NEP score than “Other” nationality.

\section{Discussion}

The present study indicated that whale watching in Alaska has potential to be a conduit for conservation and protection of whales and the environment. The conservation benefits identified in this study include spreading knowledge and awareness about whales, whale watching, and whale-watching guidelines and regulations and increasing support

Table 7

Linear Modeling Output for Proenvironmental Attitudes (NEP Value) Including Predictor Variables of Behavior ("Recycle at Home" and "Belong to an Environmental or Conservation Organization") and Attitudes Towards Whale Watching, While Controlling for SDRS and Demographics (Nationality, Sex)

\begin{tabular}{lcccc}
\hline & Estimate & $S E$ & $t$ Value & $\operatorname{Pr}(>|t|)$ \\
\hline (Intercept) & 24.224 & 0.416 & 58.289 & $<0.001$ \\
Recycle: No & Ref & Ref & Ref & Ref \\
Recycle: Yes & 0.826 & 0.238 & 3.478 & 0.001 \\
Belong to an organization: No & Ref & Ref & Ref & Ref \\
Belong to an organization: Yes & 1.724 & 0.306 & 5.626 & $<0.001$ \\
Importance Factor: Getting close & Ref & Ref & Ref & Ref \\
Importance Factor: Boat size & 0.452 & 0.425 & 1.063 & 0.288 \\
Importance Factor: See behaviors like feed or leap & 0.217 & 0.207 & 1.051 & 0.293 \\
Importance Factor: Long time with whales & 0.069 & 0.444 & 0.154 & 0.877 \\
Importance Factor: Only boat & 0.370 & 0.819 & 0.452 & 0.651 \\
Importance Factor: Being respectful to whales & 1.483 & 0.271 & 5.466 & $<0.001$ \\
See whales in the wild: Very important & Ref & Ref & Ref & Ref \\
See whales in the wild: Somewhat important & -0.712 & 0.311 & -2.290 & 0.022 \\
See whales in the wild: Not important & 0.166 & 0.220 & 0.753 & 0.451 \\
Boats have negative effects: Agree & Ref & Ref & Ref & Ref \\
Boat have negative effects: Neutral & -0.663 & 0.264 & -2.511 & 0.012 \\
Boat have negative effects: Disagree & -0.823 & 0.268 & -3.067 & 0.002 \\
Regulations important: Agree & Ref & Ref & Ref & Ref \\
Regulations important: Neutral & -2.816 & 0.540 & -5.213 & $<0.001$ \\
Regulations important: Disagree & -0.102 & 0.248 & -0.411 & 0.681 \\
SDRS & 0.177 & 0.067 & 2.646 & 0.008 \\
Nationality: Other & Ref & Ref & Ref & Ref \\
Nationality: USA & -1.628 & 0.248 & -6.550 & $<0.001$ \\
Sex: Female & Ref & Ref & Ref & Ref \\
Sex: Male & -0.592 & 0.184 & -3.223 & 0.001 \\
\hline & & & &
\end{tabular}

Note. Ref $=$ reference group in the analysis. Significant values are shown in italic. 
of guidelines and regulations for the protection of whales. Meanwhile, getting close to whales and seeing interesting behaviors like feed or leap (e.g., an activity that breaks the surface of the water) remained the most important factors in a participant's whale watch. With regulations in place prohibiting close encounters with whales, fostering passenger understanding of whales and whale watching will be essential in managing expectations of these importance factors. Furthermore, participants had a higher likelihood of strongly supporting guidelines and regulations if they indicated that boats can have a negative impact on whales or were aware of guidelines and regulations. Lastly, participants with higher overall proenvironmental attitudes were more likely to agree that boats can have a negative impact on whales and acknowledge the importance of being respectful to whales.

Following the whale-watching tour, the majority of participants indicated their whale-watching tour in Juneau was the primary source of knowledge about whales and there was a significant increase in participant awareness of whale-watching guidelines and regulations. Other studies of whale-watching tourism have indicated that participants want to learn (Filby et al., 2015; Lück, 2003, 2015; Russell \& Hodson, 2002) and are more satisfied with their tour when there is information provided about whales and the marine environment (Andersen \& Miller, 2006). Other studies argue that information from whale watches is usually not retained due to lack of background knowledge prior to the whale watch and frequent distractions (Malcolm \& Duffus, 2003), as well as the absence of structured education programs (Stamation et al., 2007). However, the present study determined that gains can be made in knowledge and awareness from whale watching immediately after and 6 months after the tour, despite the majority of participants being first-time whale watchers. Furthermore, while the majority of participants in the present study did not correctly identify all of the guidelines and regulations, the percentage of correct responses significantly increased between the PRE versus POST6M and POST versus POST6M. Knowledge gains were not immediately demonstrated after the whale watch, but it may have allowed passengers to be more open to messages about whales and whale watching after the experience.
Across all survey groups, the most important factors in determining the quality of the whale watch were getting close to the whales and seeing interesting behaviors like feed or leap. Awareness of whale-watching guidelines/regulations and knowledge of the 100-yard distance regulation did not affect participants' attitudes regarding the importance of getting close to whales. The importance of close encounters and observing interesting behaviors could largely be due to perceptions of whales from the media and the way whale watching is advertised. This study indicated that the majority of PRE participants received their information from TV and movies, which can sometimes feature false perceptions about viewing whales and the behaviors frequently seen. As mentioned by Malcolm and Duffus (2003), people may not realize that movies, TV, and pictures are the result of hundreds of hours of work and that they are often only shot in perfect conditions. Furthermore, whale-watching companies will advertise, "Guaranteed Sightings" next to a photo of a breaching whale or a close-up of a whale (Malcolm \& Duffus, 2003).

In contrast to the present study, Filby et al. (2015) determined that participant importance for close encounters in swim-with dolphin tourism decreased over time. Meanwhile, seeing dolphins in their natural environment remained a factor of very-high importance for participants (Filby et al., 2015). Similarly, in the present study, the majority of participants indicated that it was very important for them to personally see humpback whales in the wild.

Of participants that were aware of guidelines and regulations, participants that correctly selected the regulation "Maintaining a distance of at least 100 yards from humpback whales" and guideline "Staying with humpback whales for a maximum of 30 minutes" significantly increased between the PRE versus POST and PRE versus POST6M. These limitations are likely the most memorable of the guidelines and regulations because they influence passenger viewing experience.

Participants in the present study largely agreed or strongly agreed that "observing whales from boats can have positive impacts on people," with the percentage that strongly agreed significantly increasing 6 months later. These results mirror dolphin-swim participant responses in Australia, in which the 
proportion of passengers that agreed or strongly agreed that "observing dolphins from boats can have a positive impacts on people" grew between the surveys before, after, and 6 months after a tour (Filby et al., 2015). Therefore, the positive impact may be most strongly felt over time. Orams (2000) indicated that the presence of whales alone can positively influence whale watcher satisfaction. Across all survey groups, the majority of participants were neutral in response to "observing whales from boats can have negative impacts on whales." However, while there was a significant increase from PRE to POST in participants that disagreed that boats have negative impacts on whales, there was a significant increase in participants that agreed 6 months later. This trend has also been demonstrated in dolphinswim tourism, in which following a dolphin-swim the percentage of passengers that agreed or strongly agreed that "observing dolphins from boats can have negative impacts on dolphins” decreases following a dolphin-swim but is highest before and 6 months after (Filby et al., 2015). Furthermore, the majority of participants across all survey groups agreed or strongly agreed that "Following whale watch guidelines and regulations is important for the protection of whales," and the Strongly agree significantly increased between PRE versus POST and PRE versus POST6M. Since most wildlife tourists do not desire to cause harm to the environment in which they are visiting (Curtin, 2010; Wiener, Needham, \& Wilkinson, 2009), they may be more likely to recognize their possible impact 6 months later rather than immediately after the whale watch. Additionally, after participants become aware of guidelines and regulations during a whale watch, it is likely that they more positively perceive the existence of guidelines and regulations responsible for reducing negative impacts on whales.

The present study indicated that participants that were aware of whale-watching guidelines and regulations were significantly more likely to indicate strong support for guidelines and regulations for the protection of humpback whales than those that were not. This supports findings by Filby et al. (2015) that as participants become knowledgeable about guidelines and regulations, they are more likely to support them. Participants who are aware of guidelines and regulations are less likely to be dissatisfied with viewing distance (Andersen \&
Miller, 2006). Operators can better alleviate disappointment and negative perceptions associated with the absence of close encounters by educating passengers about existing guidelines and regulations and why they are in place. Filby et al. (2015) also determined that passengers with knowledge of regulations are more satisfied and ultimately can positively reinforce tour operator compliance to regulations. By managing expectations of participants and emphasizing conservation messages on trips, participants may be more satisfied with their overall experience. This indicates that operators can follow whale-watching guidelines and regulations without risking passenger enjoyment. Also, in regions with low enforcement of regulations, there is a low likelihood of operator adherence to guidelines and regulations (Filby et al., 2015; Kessler \& Harcourt, 2013). In such cases, education can be a useful tool in increasing operator compliance.

Proenvironmental attitudes, measured by the NEP-based scale, were similar between survey groups. Other studies have similarly indicated that, over time, proenvironmental attitudes do not increase as a result of ecotourism (Beaumont, 2001). However, participant proenvironmental attitudes largely correlated with attitudes towards whale watching. Participants who indicated importance for operators being respectful to whales and participants with greater concern for the impact of vessels on whales had a higher NEP score. Interestingly, in response to "Following whale watch guidelines and regulations is important for the protection of whales," participants that selected Neutral had a significantly lower NEP score than those that agreed, but those that disagreed did not have a significantly different NEP score than those that agreed. While protection of resources is a fundamental proenvironmental attitude, how people believe it should be protected may vary. The connection between attitudes towards the conservation and protection of whales may not always extend to that of general protection of the environment and vice versa (Stamation et al., 2007). However, the present study supports results of Christensen et al. (2009), which indicated that whale watchers that were stronger in their proenvironmental values were more likely to be aware of effects of their behavior on whales and their habitat. The incorporation of social desirability as a control also proved to be an 
important factor in modeling for proenvironmental values because SDRS significantly increased with each unit increase of NEP score. Future research should include SDRS to increase quality of selfreported answers.

Following a whale watch, the majority of passengers were very likely to participate in another whale watch and tell friends and family about what they learned. However, participants were Somewhat likely to join or donate to an environmental or conservation organization. Within 6 months, participants were unlikely to have gone on another whale watch or ecotourism trip or to have joined or donated to an environmental or conservation organization but were very likely to have told friends and family about what they learned. This supports other studies that have also indicated that participants are more likely to engage in proenvironmental behaviors that require less commitment regarding effort, time, and/or money (Filby et al., 2015; Mayes \& Richins, 2009). The majority of participants in all survey groups engaged in at least one environmental behavior, with recycling at home being the highest. This reflects the concern of Beaumont (2001) that ecotourism may be just "preaching to the converted" and that little proenvironmental behavioral gain occurs from ecotourism because participants who seek those experiences are already engaging in proenvironmental behaviors.

Other studies argue that while proenvironmental behavioral intentions and environmental knowledge are high after a whale watch, participants were not likely to adopt or maintain these changes when they returned home (Beaumont, 2001; Stamation et al., 2007). Some proenvironmental behaviors may have barriers for adoption such as lack of knowledge on how to adopt, level of effort necessary (Pearson et al., 2012), or it is not possible to adopt (e.g., recycling at work). In order to change behavior, Orams (1997) indicated that educational programs must be structured to do so. Whale-watching programs should be encouraged to develop programs that motivate participants to adopt proenvironmental behaviors (Packer \& Ballantyne, 2012). The likelihood of participants supporting the protection of marine mammals increases when conservation messages and actions are incorporated into the whale-watching tour (Zeppel \& Muloin, 2008). The most effective way to enable participants to engage in conservation actions is to provide opportunities to take action on the trip itself (Orams, 1997).

All companies in which participants were surveyed belonged to the Whale SENSE program, indicating that their staff had received additional training and had agreed to abide by additional guidelines. In comparison to a preliminary study conducted by Lopez and Pearson (2017) of the Juneau whale-watching industry prior to the inception of Whale SENSE in 2015, awareness of whale watch guidelines and regulations increased from $49 \%$ to $71 \%$. While the previous study did not measure the long-term effects, the present study also suggested an additional increase in awareness 6 months later (85\%). This could indicate that the implementation of the Whale SENSE program has fostered increases in participant awareness of guidelines and regulations. However, after a whalewatching tour in both studies, the majority of participants indicated that their whale watch was their primary source of information about whales, that most participants were very likely to go on another whale watch or tell friends and family about what they learned, and that the primary factors of importance were getting close to the whales and seeing interesting behaviors like feed or leap.

The importance of close encounters in Lopez and Pearson (2017) and the present study supports the finding in this study that awareness about guidelines and regulations and knowledge about whales alone is not enough to influence the importance of getting close to whales for participants. It will be important to evaluate the quality of information being presented about the purpose of guidelines and regulations on whale-watching tours to determine aspects that could be improved for training. However, as determined in the present study, the majority of whale-watching participants indicated close encounters as the single most important factor in their whale watch before even going on the whale watch. Therefore, an important consideration for operators is to better manage expectations before participants begin their whale watch. Ultimately, by using media that reflects compliance with guidelines and regulations and incorporating educational messages into advertisements, operators can better support conservation messages and responsible viewing practices. 


\section{Conclusions}

As whale watching continues to grow in Juneau and throughout the world, incorporating education and conservation into tours will be increasingly important. Participants in this study demonstrated that whale watching can increase awareness, knowledge, and support of whale-watching guidelines and regulations. By managing expectations for close encounters with whales through education, operators can be encouraged to abide by guidelines and regulations without sacrificing participant satisfaction. The implementation of voluntary programs, such as Whale SENSE, has shown promise in encouraging participant awareness about whales and whale watching. Therefore, structured and comprehensive educational programs can be used to better support management objectives seeking to conserve and protect whales and their environment. This study indicates that educational programs on whale-watching tours should be considered as a management tool in encouraging operator compliance.

\section{Acknowledgments}

The authors wish to thank Juneau Whale Watch, Dolphin Jet Boat Tours, and Allen Marine Tours and their staff for their assistance in survey data collection, and Madison Bargas, Taelor Brandon, Gabrielle Lopez, and Robert Schuler for helping with survey data entry. The research was sponsored by Alaska Sea Grant, University of Alaska Fairbanks (project \#R/112-05), with funds from the National Oceanic and Atmospheric Administration (grant NA14OAR4170079), and from the University of Alaska with funds appropriated by the state of Alaska.

\section{Biographical Notes}

Alicia Schuler received her M.Sc. in Fisheries from the University of Alaska Fairbanks and her B.A. in Environmental Science from the University of Florida. Her research to date concentrates on the impact of anthropogenic activities on cetaceans.

Heidi Pearson is an Associate Professor of Marine Biology at the University of Alaska Southeast where she teaches courses in marine vertebrate biology and conducts marine mammal research. Her research focuses on the behavior, ecology, and conservation of cetaceans and sea otters. She earned her Ph.D. in Wildlife and Fisheries Sciences from Texas A\&M University and her B.S. in Biological Anthropology and Anatomy, and Biology from Duke University. She has been an active member of the Society for Marine Mammalogy since 2003.

\section{References}

Andersen, M., \& Miller, M. (2006). Onboard marine environmental education: whale watching in the San Juan Islands, Washington. Tourism in Marine Environments, 2(2), 111-118.

Beaumont, N. (2001). Ecotourism and the conservation ethic: recruiting the uninitiated or preaching to the converted? Journal of Sustainable Tourism, 9(4), 317-341.

Bejder, L., Samuels, A., Whitehead, H., Gales, N., Mann, J., Connor, R., . . . Krutzen, M. (2006). Decline in relative abundance of bottlenose dolphins exposed to long-term disturbance. Conservation Biology, 20(6), 1791-1798. doi: 10.1111/j.1523-1739.2006.00540.x

Carlson, C. (2013). A review of whale watch guidelines and regulations around the world version 2012. Retrieved from https://iwc.int/index.php?cID=3107\&cType=document

Cartwright, R., Gillespie, B., Labonte, K., Mangold, T., Venema, A., Eden, K., \& Sullivan, M. (2012). Between a rock and a hard place: habitat selection in female-calf humpback whale (Megaptera novaeangliae) pairs on the Hawaiian breeding grounds. PLoS One, 7(5), e38004. doi: 10.1371/journal.pone.0038004

Christensen, A., Needham, M. D., \& Rowe, S. (2009). Whale watchers' past experience, value orientations, and awareness of consequences of actions on the marine environment. Tourism in Marine Environments, 5(4), 271-285.

Christensen, A., Rowe, S., \& Needham, M. D. (2007). Value orientations, awareness of consequences, and participation in a whale watching education program in Oregon. Human Dimensions of Wildlife, 12(4), 289-293. doi: 10.1080/10871200701442999

Curtin, S. (2010). Managing the wildlife tourism experience: The importance of tour leaders. International Journal of Tourism Research, 12(3), 219-236. doi: 10.1002/ jtr.747

Di Clemente, J., Christiansen, F., Pirotta, E., Steckler, D., Wahlberg, M., \& Pearson, H. C. (2018). Effects of whale watching on the activity budgets of humpback whales, Megaptera novaeangliae (Borowski, 1781), on a feeding ground. Aquatic Conservation: Marine Freshwater Ecosystem, 28(4), 1-11. doi: 10.1002/aqc.2909

Dugan, D., Fay, G., Griego, H., \& Colt, S. (2009). Naturebased tourism in Southeast Alaska (ISER working paper 2009.1). Retrieved from https://iseralaska.org/static/ legacy_publication_links/workingpapers/WP2009\% 201_SEnbt_final.pdf

Filby, N. E., Stockin, K. A., \& Scarpaci, C. (2015). Social science as a vehicle to improve dolphin-swim tour 
operation compliance? Marine Policy, 51, 40-47. doi: 10.1016/j.marpol.2014.07.010

Finkler, W., \& Higham, J. (2004). The human dimensions of whale watching: An analysis based on viewing platforms. Human Dimensions of Wildlife: An International Journal, 9(2), 103-117. doi: 10.1080/10871200490441757

Gralton, A., Sinclair, M., \& Purnell, K. (2004). Changes in attitudes, beliefs, and behaviour: A critical reivew of research into the impacts of environmental education iniatives. Australian Journal of Environmental Education, 20(2), 41-52.

Hays, R. D., Hayashi, T., \& Stewart, A. (1989). A five-item measure of socially desirable response set. Educational and Psychological Measurement, 49, 629-636.

Higginbottom, K., Northrope, C., \& Green, R. (2001). Positive effects of wildlife tourism on wildlife. Wildlife Tourism Research Report Series, 6, 108.

International Whaling Commission. (2018). International Convention for the Regulation of Whaling, 1946, Schedule as amended by the Commission at the 67th Meeting. Paper presented at the 2018 Commission Meeting, Florianópolis, Brazil.

Kessler, M., \& Harcourt, R. (2013). Whale watching regulation compliance trends and the implications for management off Sydney, Australia. Marine Policy, 42, 14-19. doi: 10.1016/j.marpol.2013.01.016

Lopez, G., \& Pearson, H. C. (2017). Can whale watching be a conduit for spreading educational and conservation messages? A case study in Juneau, Alaska. Tourism in Marine Environments, 12(2), 95-104. doi: 10.3727/1544 27316X14779456049821

Lück, M. (2003). Education on marine mammal tours as agent for conservation-But do tourists want to be educated? Ocean \& Coastal Management, 46, 943-956.

Lück, M. (2015). Education on marine mammal toursBut what do tourists want to learn? Ocean \& Coastal Management, 103, 25-33. doi: 10.1016/j.ocecoaman. 2014.11.002

Lusseau, D., \& Bejder, L. (2007). The long-term consequences of short-term responses to disturbance experiences from whalewatching impact assessment. International Journal of Comparitive Psychology, 20, 228-236.

Luzar, E. J., Diagne, A., Gan, C., \& Henning, B. R. (1995). Evaluating nature-based tourism using the new environmental paradigm. Journal of Agriculture and Applied Economics, 27(2), 544-555.

Malcolm, C. D., \& Duffus, D. (2003). Can whale-watching convey an important message of conservation?: An initial perspective from British Columbia, Canada. Prairie Perspectives, 175-190.

Mayes, G., \& Richins, H. (2009). Dolphin watch tourism: two differing examples of sustainable practices and proenvironmental outcomes. Tourism in Marine Environments, 5(2-3), 201-214.

McDowell Group. (2017). Juneau Visitor Profile and Economic Impact Study 2016. Prepared for Travel Juneau. Retrieved from https://www.alaskatia.org/Research/ juneau-visitor-profile-and-economic-impact-reportoctober-2017.pdf

National Oceanic and Atmospheric Administration. (2016). Endangered and Threatened Species; Identification of 14 distinct population segments of the humpback whale (Megaptera novaeangliae) and revision of species-wide listing. Federal Register: U.S. Department of Commerce. Retrieved from https://www.federalregister.gov/ documents/2016/09/08/2016-21276/endangeredand-threatened-species-identification-of-14-distinctpopulation-segments-of-the-humpback

NOAA Fisheries. (2019). Alaska marine mammal viewing guidelines and regulations. Retrieved from https://www. fisheries.noaa.gov/alaska/marine-life-viewing-guidelines/alaska-marine-mammal-viewing-guidelines-andregulations

NOAA Fisheries, \& Whale and Dolphin Conservation. (2018). Promoting responsible whale watching. Retrieved from www.whalesense.org

O’Connor, S., Campbell, R., Cortez, H., \& Knowles, T. (2009). Whale Watching Worldwide: tourism numbers, expenditures and expanding economic benefits. A special report from the International Fund for Animal Welfare. Economists at Large. Yarmouth MA, USA. Retrieved from https://www.cms.int/sites/default/files/document/ BackgroundPaper_Aus_WhaleWatchingWorldwide_ $\underline{0 . p d f}$

Orams, M. B. (1997). The effectiveness of environmental education: Can we turn tourists into 'greenies'? Progress in Tourism and Hospitality Research, 3, 295-306.

Orams, M. B. (2000). Tourists getting close to whales, is it what whale-watching is all about? Tourism in Marine Environments, 21, 561-569.

Packer, J., \& Ballantyne, R. (2012). Comparing captive and non-captive wildlife tourism. Annals of Tourism Research, 39(2), 1242-1245.

Parsons, E. C. M. (2012). The negative impacts of whalewatching. Journal of Marine Biology, 2012, 1-9. doi: 10.1155/2012/807294

Pearson, H. C., Dawson, L. N., \& Radecki Breitkopf, C. (2012). Recycling attitudes and behavior among a clinic-based sample of low-income Hispanic women in southeast Texas. PLoS One, 7(4), e34469. doi: 10.1371/ journal.pone.0034469

Rain Coast Data. (2018). Southeast Alaska by the Numbers 2018. Retrieved from http://www.raincoastdata. com/portfolio/southeast-alaska-numbers-2018

Radecki Breitkopf, C., \& Pearson, H. C. (2009). A theorybased approach to understanding follow-up of abnormal pap tests. Journal of Health Psychology, 14(3), 361-371. doi: $10.1177 / 1359105308101674$.

Russell, C. L., \& Hodson, D. (2002). Whalewatching as critical science education? Canadian Journal of Science, Mathematics and Technology Education, 2(4), 485-504. doi: 10.1080/14926150209556537

Schuler, A. R., Piwetz, S., Di Clemente, J., Steckler, D., Mueter, F., \& Pearson, H. C. (2019). Humpback whale 
movements and behavior in response to whale-watching vessels in Juneau, AK. Frontiers in Marine Science, 6(710), 13. doi: 10.3389/fmars.2019.00710

Stamation, K. A., Croft, D. B., Shaughnessy, P. D., Waples, K. A., \& Briggs, S. V. (2007). Educational and conservation benefit of whale watching. Tourism in Marine Environments, 4(1), 44-55.

Steele, P. (1993). Ecotourism: An economic analysis. Journal of Sustainable Tourism, 3(1), 29-44.
Wiener, C. S., Needham, M. D., \& Wilkinson, P. F. (2009). Hawaii's real life marine park: Interpretation and impacts of commercial marine tourism in the Hawaiian Islands. Current Issues in Tourism, 12(5-6), 489-504. doi: $\underline{10.1080 / 13683500902736855}$

Zeppel, H., \& Muloin, S. (2009). Conservation and education benefits of interpretation on marine wildlife tours. Tourism in Marine Environments, 5(1-3), 215-227. doi:10.3727/154427308787716802 